\title{
As espécies tributárias no ordenamento jurídico brasileiro
}

\author{
Octavio Campos Fischer*
}

Sumário: Introdução; 1.Teoria bipartida; 2.Teoria quadripartida; 3.Teoria qüinquipartida; 4.Teoria tripartida; 5.Conclusões.

\section{Resumo}

O presente texto versa sobre as diversas concepções existentes na doutrina brasileira acerca das espécies tributárias. As várias obras pesquisadas apontaram para a existência de quatro posições entre os mais diversos autores, quais sejam, a bipartida, a tripartida, a quadripartida e a qüinqüipartida. Por aderirmos à teoria tripartida, cujos motivos seguem abaixo, foi ela, nas variações apresentadas pelos autores que a defendem, analisada por último

\section{Introdução}

Aquele que, interessado pelo estudo do direito tributário, deparar-se com o capítulo das espécies tributárias, sentir-se-á como que circulando ...nos corredores dum manicômio jurídico-tributário. ${ }^{1}$ Isto porque uma boa parte da doutrina, ao discorrer sobre os impostos, as taxas, as contribuições de melhoria, as contribuições especiais e os empréstimos compulsórios pelo mais puro arbítrio e sem nenhuma cientificidade - ou faz tábula rasa da nossa Constituição ou passa ao largo da análise de quais destes tributos

* Advogado, mestrando em, Pireito Tributário no Curso de Pós-Graduação em Direito/Mestrado da Faculdade de Direito da UFPR.

1 Expressão utilizada por Alfredo Augusto Becker (Teoria geral do direito tributário, $2^{\mathrm{a}}$ ed., São Paulo, Saraiva, 1972, p. 06) e que foi largamente difundida em nossa doutrina.

R. Fac. Direito, Curitiba, a. 28, n.28, 1994/95, p.227-248 
deveriam ser considerados espécies tributárias autônomas, gerando, pois, uma grande variedade de opiniões acerca deste tema. ${ }^{2}$

Assim, pela existência de alguns dispositivos constitucionais, (Art. $145,148,149),{ }^{3}$ acabamos por nos defrontar com quatro posições sobre o número de figuras tributárias autônomas em nosso ordenamento jurídico, quais sejam, a teoria bipartida, a teoria tripartida, a teoria quadripartida e a teoria qüinqüipartida. A primeira defende a existência autônoma dos impostos e das taxas; a segunda, embora com algumas divergências entre os autores que a ela se filiam, adota a distinção entre tributos vinculados (impostos) e não-vinculados (taxas e contribuições ou contribuição de melhoria); a terceira tem, em geral, como espécies autônomas, os impostos, as taxas, a contribuição de melhoria e os empréstimos compulsórios; e $a$ quarta autonomiza todas as espécies contidas nos dispositivos constitucionais supracitados.

Destarte, não pretendemos, aqui, fazer maiores incursões sobre cada uma destas posições. Queremos, sim, apenas demonstrar quais são os seus

2 Deixamos de lado as opiniões tendentes a excluir os empréstimos compulsórios do regime jurídico-tributário. Dentre os autores de relevo que assim entendem, podemos destacar o prof. Edvaldo Brito (As taxas, In: $43^{\text {rd }}$ Congress of the International Fiscal Association, Seminário "E": El sistema tributario brasileño, São Paulo, Acadêmica, 1989 , p. 20) e o prof. Hugo de Brito Machado, cujo pensamento será melhor demonstrado quando falarmos da posição qüinqüipartida. Também, Lúcia Valle Figueiredo (Estevão Horvath, Empréstimo compulsório sobre veículos, In: Revista de Direito Tributário, São Paulo, RT, a. 12, jan./mar.-1988, n.43, p. 264-5), Eduardo Marcial F. Jardim (Manual de direito financeiro e tributário, São Paulo, Saraiva, 1993, p. 81) e Hamilton Dias de Souza (Tributos federais, In: A Constituição Brasileira - 1988: interpretações, Rio de Janeiro, Forense Universitária, 1988, p. 311-21).

Entrementes, o Supremo Tribunal Federal, revendo a Súmula $\mathrm{n}^{\circ} 418$ ("O empréstimo compulsório não é tributo..."), faz algum tempo passou a aceitar a natureza tributária do empréstimo compulsório (Aliás, sobre o assunto, ver a sentença proferida por Américo Masset Lacombe apud Estevão Horvath, Empréstimo..., op. cit., p. 236-52).

$3 \mathrm{O}$ art. 145, da CF, dispõe que as quatro pessoas políticas da Federação poderão instituir impostos, taxas e contribuição de melhoria; o art. 148, que a União poderá instituir, mediante lei complementar, empréstimos compulsóriose o art. 149, que a União poderá instituir contribuições sociais - de intervenção no domínio econômico e de interesse das categorias profissionais ou econômicas; e o parágrafo único, do art. 149, que os Estados, o Distrito Federal e os Municípios poderão instituir contribuição para o custeio de sistema de previdência e assistência social. 
principais fundamentos, procurando, ao final, expor, resumidamente, a posição que reputamos a melhor (teoria tripartida).

Iniciaremos, por conseguinte, com a teoria bipartida.

\section{Teoria bipartida}

Dentre todas as que aqui serão expostas, a que sustenta a existência de apenas duas espécies autônomas (impostos e taxas),é a que menor número de autores abriga. Por outro lado, teve ela como aliado um dos maiores tributaristas que este país - e, talvez, toda a América Latina - já conheceu: Alfredo Augusto Becker, falecido jurista gaúcho, que, na sua Teoria Geral do Direito Tributário, ${ }^{4}$ defendia a existência de apenas duas espécies autônomas de tributos: os impostos e as taxas.

Para este autor, o núcleo da hipótese de incidência era a base de cálculo, que, por ser exclusiva para cada tributo, ${ }^{5}$ era ...o único critério objetivo e jurídico para aferir o gênero e a espécie jurídica de cada tributo.... ${ }^{6}$ Assim sendo, a contribuição de melhoria não constituiria gênero jurídico específico de tributo, pois, consoante ...a sua base de cálculo (núcleo da hipótese de incidência), a contribuição (de melhoria) será uma espécie do gênero impôsto de renda ou uma taxa,... (sic). ${ }^{7}$ Seria a contribuição de melhoria uma espécie de imposto (de renda) se a sua base de cálculo consistisse na mais-valia do imóvel; por outro lado, seria uma espécie de taxa se a base de cálculo fosse o custo do serviço estatal, que constituiria a causa da referida mais-valia. ${ }^{8}$

No tocante às contribuições parafiscais, Becker foi enfático ao assinalar que... não constituem uma natureza jurídica de tributo "sui generis", nem

4 Alfredo Augusto Becker, Teoria geral..., op. cit., p. 621

5 Alfredo Augusto Becker, Teoria geral..., op. cit., p. 339, Interessante seria verificarmos como Becker chegou a essa conclusão, partindo da análise da hipótese de incidência (Teoria geral, op. cit., p. $331^{\mathrm{e} e}$ ss.) feita por A. D. Giannini (I concetti fondamentali de diritto tributario, Torino, UTET, 1956).

6 Alfredo Augusto Becker, Teoria geral..., op. cit., p. 345.

7 Alfredo A. Becker, Teoria geral..., op. cit., p. 351.

8 Alfredo A. Becker, Teoria geral..., op. cit., p. 351-2.

R. Fac. Direito, Curitiba, a.28, n.28, 1994/95, p. 227-248 
tributo de natureza mista, porém, em determinados casos, são simples impostos com destinação determinada e, noutros, verdadeiras taxas. (...) E a "contribuição parafiscal" possui a referida natureza jurídica porque a destinação do tributo, a sua maior ou menor proporção (em relação à base de cálculo) e a posição do sujeito passivo em relação à hipótese de incidência do tributo, não exercem qualquer influência sôbre a natureza jurídica do tributo (sic). ${ }^{9}$

Com relação aos empréstimos compulsórios, Becker defendia serem eles verdadeiros impostos restituiveis, pois o ... fato de o Estado devolver ao contribuinte em dinheiro...o valor do tributo...não desqualifica a sua natureza jurídica de tributo, porque a destinação...não altera a sua natureza jurídica. que continuará sendo a de tributo. (...) Ora, a devolução do montante do tributo ao contribuinte é uma (entre outras) das destinações determinadas àquele tributo e tal fenômeno ocorre também com outros tributos. ${ }^{10}$

Assim, apesar de toda sua genialidade, Becker, quanto às espécies tributárias, preferiu seguir os passos de Sainz de Bujanda e Pontes de Miranda, ${ }^{11}$ ao invés de adotar a posição tripartida, que, no Brasil, começava a aflorar com Baleeiro.

Atualmente, poucos são aqueles que, após o advento da Constituição de 1988, sustentam uma divisão bipartida dos tributos, sendo, destes, a posição do prof. Eduardo Marcial Ferreira Jardim a mais interessante, por entender que Os tributos,..., se desdobram em impostos e taxas, já que, para o mesmo em posição sui generis - existem ...três prestações de direito público: tributos, contribuições parafiscais e empréstimos compulsórios. ${ }^{12}$

9 Alfredo A. Becker, Teoria geral..., op. cit., p. 350.

10 Alfredo A. Becker, Teoria geral..., op. cit., p. 358.

11 Fernando Sainz de Bujanda, Estructura jurídica del sistema tributário, In: Revista de Derecho Financiero y de Hacienda Pública, Madrid, 1961, vol. IX, fasc. 41, p. 41; e Pontes de Miranda. Comentários à Constituição de 1967, Vol. II, São Paulo, RT, 1967, p. 351: "Rigorosamente, a dicotomia "taxa, imposto" é exaustiva. Todo tributo pecuniário ou é impôsto ou é taxa" (sic).

12 Eduardo M. F. Jardim. Manual..., op. cit., p. 81. Nesta obra, o autor sustenta posicionamento por ele anteriormente defendido (cfe.: Instituições de direito tributário, São Paulo, Aquarela, 1988, p. 57-9 e 80-4). 


\section{Teoria quadripartida}

Outra posição minoritária no Brasil é aquela que sustenta a existência de quatro figuras autônomas. Neste particular, é de se destacar o entendimento do prof. Arnaldo Borges, que apregoa a existência autônoma dos impostos, das taxas, das contribuições de melhoria e das contribuições especiais. ${ }^{13}$ Por contribuições especiais, interessante notar, este autor coloca como exemplo $o$ pedágio, que deve ser pago pelo uso de um bem público, no caso, as rodovias. Assim, tais contribuições deveriam diferençar-se dos demais tributos e, em especial, das taxas, porque estas são cobradas pela utilização de serviços públicos, enquanto aquelas, pela utilização de bens públicos. Entretanto, tal colocação não passa pelo crivo da pena de Sacha Calmon Navarro Coêlho, para quem o pedágio ...tanto pode ser preço como taxa, dependendo do regime jurídico que venha a ser adotado para institui-lo e cobrá-lo. Uma coisa, porém, é certa, não se cobra pedágio, seja taxa, seja preço, pela mera disponibilidade das vias trafegáveis, ${ }^{4}$ o que nos faz refutar a idéia de que 0 pedágio seria uma espécie autônoma de tributo, colocada sob o manto de contribuição especial.

Quanto às contribuições parafiscais e aos empréstimos compulsórios, Arnaldo Borges acompanha a doutrina majoritária, no sentido de que não constituem espécies autônomas, podendo ser considerados ou como taxas ou como impostos.

No mesmo sentido, também, José Petrelli Gastaldi, antigo professor da UFPR, tinha que as espécies tributárias eram: impostos, taxas, contribuições e pedágio. ${ }^{15}$

Por outro lado, como variante dentro do posicionamento ora destacado, Fábio Fanuchi - em posição mais coerente - defendia a existência autônoma dos impostos, das taxas, dos empréstimos compulsórios e das contribuições. ${ }^{16}$

13 Arnaldo Borges, Introdução ao direito tributário, São Paulo, RT, 1992, p. 39-40.

14 Sacha Calmon N. Coêlho, Comentários à Constituição de 1988: sistema tributário, $5^{\mathrm{a}}$ ed., Rio de Janeiro, Forense, 1993, p. 69-70.

15 José P. Gastaldi, Iniciação ao curso de direito tributário, São Paulo, Saraiva, 1965, p. 30-2.

16 Fábio Fanuchi, Curso de direito tributário, v. I, $4^{a}$ ed., São Paulo, Editora Resenha Tributária Ltda., p. 59-60.

R. Fac. Direito, Curitiba, a.28, n.28, 1994/95, p.227-248 
Estas últimas englobariam as contribuições de melhoria e todas as demais contribuições previstas em nosso ordenamento jurídico-tributário. Já os empréstimos compulsórios, tendo características peculiares em relação à̀ demais espécies tributárias, deveriam ser considerados como espécie autônoma de tributo.

\section{Teoria qüinqüipartida}

A posição qüinqüipartida, ao contrário das duas já mencionadas, é a que acolhe, juntamente com a tripartida, o maior número de seguidores. Dentre vários, buscamos trazer à colação algumas das manifestações mais expressivas.

O prof. Celso Ribeiro Bastos sustenta que as espécies tributárias autônomas são os impostos, as taxas, as contribuições de melhoria, os empréstimos compulsórios e as contribuições sociais. Seus argumentos são no sentido de que Do estrito ponto de vista do Direito Constitucional, conhece-se a situação: o art. 145 prevê os impostos, as taxas e a contribuição de melhoria, dando a entender até que seriam os únicos, posto que não enumera os demais. No entretanto, os arts. 148 e 149 contemplam, respectivamente, os empréstimos compulsórios e as contribuições sociais de intervenção no domínio econômico e de interesse das categorias profissionais ou econômicas. (...) Há, portanto, cinco modalidades tributárias contempladas na nossa Constituição. ${ }^{17}$

Quanto à divisão entre tributos vinculados e não-vinculados (que adiante será analisada), o autor em tela entende que se deve questionar se a mesma ...é...útil ou não à luz do direito positivo brasileiro. Para nós a resposta é negativa. Na medida em que a Constituição conferiu regimes próprios a cinco modalidades tributárias diferentes, importa conhecer $o$ respectivo regime jurídico. Não nos parece que seja, portanto, uma questão de palavras diferentes a encobrir coisas idênticas.

17 Celso Ribeiro Bastos, Curso de direito financeiro e de direito tributário, São Paulo, Saraiva, 1991, p. 145.

18 Celso Ribeiro Bastos, Curso..., op. cit., p. 146. 
O prof. Hugo de Brito Machado sustenta, também, a existência de cinco espécies tributárias: os impostos, as taxas, a contribuição de melhoria, os empréstimos compulsórios e as contribuições especiais. ${ }^{19}$

É que, para este autor, o ... art. 217, do CTN, com a redação que lhe deu o Decreto-Lei n. 27, de 14.11.1966, estabeleceu que as disposições do Código não excluem a incidência e exigibilidade de outras contribuições que indica. Isto tornou evidente a existência de uma quarta espécie de tributo, integrada pelas contribuições especiais, ${ }^{20}$ que se apresentam ou como contribuições sociais (contribuições de intervenção no domínio econômico e contribuições profissionais), do art. 149 , da $\mathrm{CF} / 88$, ou como contribuições de seguridade social, nos termos do art. $195{ }^{21}$

Já em relação aos empréstimos compulsórios, entende que: Do ponto de vista de uma Teoria Geral do Direito, o empréstimo compulsório na verdade não é tributo. Ele não é receita, do ponto de vista econômico. (...) Mas no Direito positivo brasileiro o empréstimo compulsório passou a ser tratado como tributo, por força de expressa disposição da Constituição Federal de 1967 (art. 21, $2^{\circ}$, item II). (...) Temos, portanto, em nosso Sistema Tributário, cinco espécies de tributo, a saber: os impostos, as taxas, as contribuič̃es de melhoria, as contribuições especiais e os empréstimos compulsórios. ${ }^{22}$

Por fim, para além destes autores e dentre outros, na mesma linha, podemos destacar, também, as posiç̃̃es de José Eduardo Soares de Melo, ${ }^{23}$ Manoel Gonçalves Ferreira Filho, ${ }^{24}$ Ives Gandra da Silva Martins, ${ }^{25}$ Luiz

19 Hugo de Brito Machado, Curso de direito tributário, $7^{\text {a }}$ ed., São Paulo, Malheiros, 1993, p. 39-48.

20 Hugo de Brito Machado, Curso..., op. cit., p. 45.

21 Hugo de Brito Machado, Curso..., op. cit., p. 47.

22 Hugo de Brito Machado, Curso..., op. cit., p. 45-6.

23 José E. Soares de Melo, Contribuições sociais no sistema tributário, São Pauło, Malheiros, 1993, p. 90-5.

24 Manoel G. Ferreira Filho, Comentários à Constituição brasileira de 1988, v. 3, São Paulo, Saraiva, 1994, p. 91.

25 Ives G. da Silva Martins, As gontribuições especiais numa divisão qüinqüipartida dos tributos, São Paulo, Editora Resenha Tributária, 1976; Comentários à Constituição do Brasil, v. 6, t. I, São Paulo, Saraiva, 1990, p. 107-38; "Quota de contribuição sobre açúcar e álcool - adicional - inconstitucionalidade", In: Revista de Direito Tributário, São Paulo, RT, a. 12, jan./mar.-1988, n. 43, p. 168-80; e Curso de direito tributário, v.

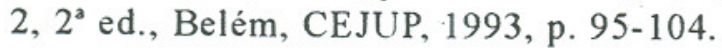

R. Fac. Direito, Curitiba, a.28, n.28, 1994/95, p.227-248 
Emygdio F. da Rosa Júnior, ${ }^{26}$ Zelmo Denari, ${ }^{27}$ Vittorio Cassone, ${ }^{28}$ Rômulo Maya $^{29}$ e Célio de Freitas Batalha. ${ }^{30}$

\section{Teoria tripartida}

Por fim, versaremos agora sobre a teoria tripartida das espécies tributárias, onde se destacam os nomes de Aliomar Baleeiro, Paulo de Barros Carvalho, Geraldo Ataliba, Rubens Gomes de Souza, Roque Antonio Carrazza, afora outros. Não fossem algumas divergências, poderíamos deixar de lado as opiniões da maioria destes autores e passar à exposição somente do pensamento daquele que desenvolveu no Brasil os fundamentos da divisão tripartida: o prof. Geraldo Ataliba. Não obstante, até porque, como dissemos, entendemos ser a teoria tripartida aquela que melhor se conforma com os ditames do nosso direito positivo, preferimos trabalhar um pouco mais detidamente com os fundamentos das opiniões de alguns autores de destaque nesta linha de pensamento.

Assim, temos com Aliomar Baleeiro ${ }^{31}$ um dos primeiros nomes a sustentar a existência de apenas três espécies de tributos, quando o mesmo já preconizava ser o empréstimo compulsório um imposto restituível ${ }^{32}$ e as contribuições parafiscais, ... formas híbridas de imposto e taxa ou, simplesmente, de imposto. ${ }^{33}$

Luiz Emygdio F. da Rosa Júnior, Manual de direito financeiro e de direito tributário, $5^{\text {a }}$ ed., Rio de Janeiro, Freitas Bastos, 1985, p. 144-6. 105 e 116.

Vittorio Cassone, Sistema tributário constitucional na Constituição de 1988 , $3^{\text {a }}$ ed., São Paulo, Atlas, p. 21 e ss.

29 Rômulo Maya, "Das contribuições especiais na Constituição de 1988," in Revista de Direito Tributário, São Paulo, RT, a. 13, out/dez-1989, n. 49, p. 68-71.

30 Célio de Freitas Batalha. "Lei complementar em matéria tributária," In Revista de Direito Tributário, São Paulo, RT, a. 13, jul./set.-1989, nº 50, p. 124.

31 Aliomar Baleeiro, Direito tributário brasileiro, $9^{\mathrm{a}}$ ed., Rio de Janeiro, Forense, 1977, p. 632. Ver também: Aliomar Baleeiro. Limitações ao poder de tributar, $5^{\text {a }}$ ed., Rio de Janeiro, Forense, 1977, p. 279 e ss. e 302.

32 Aliomar Baleeiro, Direito tributário..., op. cit., p. 114-5.

33 Aliomar Baleeiro, Direito tributário..., op. cit., p. 38 e 585, respectivamente. 
Todavia, não foi Baleeiro aquele que trouxe para a nossa doutrina a divisão entre tributos vinculados e não-vinculados (que é o fundamento da posição tripartida), mas, sim, o prof. Geraldo Ataliba, jurista de ponta na seara do direito tributário e do direito constitucional, que, com o seu Natureza Jurídica da Contribuição de Melhoria, ${ }^{34}$ já no início dos anos sessenta, marchava, com ímpeto, contra os posicionamentos formulados de modo diverso, procurando, assim, assentar as bases para o entendimento de que a contribuição de melhoria era espécie tributária inconfundível com o imposto e com a taxa. Após, no Sistema Constitucional Tributário Brasileiro, ${ }^{35}$ Ataliba começou a perscrutar as bases para a teoria dos tributos vinculados e não-vinculados, entendendo, então, que os tributos classificam-se em ...imposto e exações vinculadas à atividade pública - a segunda das quais se desdobra, por sua vez, em três subespécies: a taxa, a contribuição de melhoria e contribuição previdenciária (sic). ${ }^{36}$ Por fim, baseando-se nas lições de Achile Donato Giannini, Ataliba, com o seu livro Apontamentos de Ciência das Finanças, Direito Financeiro e Tributário ${ }^{37}$ e com o artigo Considerações em tôrno da teoria jurídica da taxa (sic) ${ }^{38}$ lança definitivamente no Brasil a teoria dos tributos vinculados e não-vinculados, aperfeiçoando-a, após, no livro Hipótese de Incidência Tributária, ${ }^{39}$ para assim impor à nossa doutrina uma posição fulcrada

34 Geraldo Ataliba, Natureza juridica da contribuição de melhoria, São Paulo, RT, 1964, p. 35 .

35 Geraldo Ataliba, Sistema constitucional tributário brasileiro, São Paulo, RT, 1968, p. 295.

36 Geraldo Ataliba, Sistema..., op. cit., p. 136-7, Com relação à contribuição previdenciária, Ataliba, ainda nesta obra, ao tratar, no cap. IX, da parafiscalidade, entende que: quando disser respeito ao empregador, assume ela feição de imposto; de outra parte, quando se referir ao empregado, terá feição de taxa (p. 204). Portanto, a contribuição previdenciária não tem característica de contribuição especial (ou tributo especial), como aliás todos os demais tributos parafiscais (p. 204). Tal explanação se mostra oportuna porque a leitura da divisão dos tributos, acima exposta, pode levar à consideração de que Ataliba se enquadrava na teoria quadripartida.

37 Geraldo Ataliba, Apontamentos de ciência das finanças, direito financeiro e tributário, São Paulo, RT, abril-1969, p. 192-9.

38 Geraldo Ataliba, "Considerações em torno da teoria jurídica da taxa." in Revista de Direito Público, São Paulo, RT, jul./set.-1969, n. 09, 1969, p. 43-54.

39 Geraldo Ataliba, Hipótese de incidência tributária..., A primeira edição foi em 1973, publicada pela Revista dos Tribunais. Atualmente, já passa da quinta. Utilizaremos, no presente texto a quinta edição, São Paulo, Malheiros, 1992, 182 p.

R. Fac. Direito, Curitiba, a.28, n.28, 1994/95, p.227-248 
eminentemente em critérios jurídicos, pois ...está na consistência da h.i., ou seja, no seu aspecto material o único critério satisfatório para uma teoria acerca das espécies tributárias. ${ }^{40}$

Sendo este aspecto a pedra de toque para uma classificação jurídica dos tributos, devemos, aqui, abrir um parêntesis e recorrer às lições de Paulo de Barros Carvalho ${ }^{41}$ e de José Roberto Vieira ${ }^{42}$ sobre a estrutura da norma tributária.

É clássica a distinção kelseniana entre norma primária e norma secundária, ${ }^{43}$ ambas formando a norma dupla ou norma complexa: ${ }^{44}$ a norma primária é aquela... que determina a conduta desejada..., enquanto que, por outro lado, a norma secundária é ...aquela que estabelece a sanção pelo descumprimento da primeira... ${ }^{45}$ Tanto uma quanto a outra ... apresentam idêntica estrutura lógica: uma hipótese e uma conseqüencia, unidas pelo conectivo ou operador deôntico, assim chamado por constituir-se num dever ser. Tal associação também é referida como cópula deôntica. ${ }^{46} \mathrm{Ou}$ seja: dado um fato A então deve ser $\mathrm{B} ;{ }^{47}$ se proprietário de um imóvel deve pagar quantia x (norma primária); se não pagar sofrerá uma sanção (norma secundária).

Da norma complexa (norma primária + norma secundária), interessanos, no presente texto, aquela que determina a conduta desejada: a norma primária, que, como registramos, apresenta uma hipótese e uma conseqüência, ligadas pelo dever ser: Dado o fato A, deve ser a conduta B. A hipótese

40 Geraldo Ataliba. Hipótese de incidência..., op. cit., p. 109, É a materialidade do conceito do fato, descrito hipoteticamente pela h.i. que fornece o critério para classificação das espécies tributárias (p.115).

41 Sobretudo, ver: Paulo de Barros Carvalho, Teoria da norma tributária $2^{\mathrm{a}}$ ed., São Paulo, RT, 1981, p. 123 ; e Paulo de Barros Carvalho. Curso de direito tributário, $5^{\mathrm{a}}$ ed., São Paulo, Saraiva, 1991, 374 p.

42 José Roberto Vieira, A regra-matriz de incidencia do IPI: texto e contexto, Curitiba, Juruá, 1993, 179 p.

43 José Roberto Vieira, A regra-matriz..., op. cit., p. 56. Cfr. Hans Kelsen, Teoria geral das normas, trad. José F. Duarte, Porto Alegre, Safe, 1986, p. 181.

44 Paulo de Barros Carvalho, Teoria da norma...op. cit., p. 29 e ss.

45 José Roberto Vieira, A regra-matriz..., op. cit., p. 56.

46 José Roberto Vieira, A regra-matriz..., op. cit., p. 57.

47 É o que comumente se chama de principio da imputação, em contrapartida ao que ocorre com as leis da natureza, regidas pelo principio da causalidade: Se A, então B. 
se refere à previsão abstrata, feita pelo legislador, do fato que faz nascer a relação jurídica tributária, ${ }^{48}$ a conseqüência, por sua vez, "...prescreverá a relação jurídica...que se vai instaurar." 49

Neste ponto, verificamos que, para melhor se delimitar o fato que, uma vez ocorrido no mundo das realidades físicas, ensejará a relação jurídico-tributária, devemos, dentro de uma operação lógico-abstrata, levar a cabo um seccionamento provisório da norma primária e, no presente caso, da hipótese de incidência. ${ }^{50}$ Tal seccionamento nos mostra que a hipótese de incidência apresenta três critérios (ou aspectos) identificadores do fato jurídico tributário (o fato que faz nascer a relação tributária), quais sejam: o critério material, o critério temporal e o critério espacial. Este "...possibilita o reconhecimento da condição que marca, no espaço, o acontecimento do fato jurídico tributário, adstringindo-o a determinada extensão do território". ${ }^{51} \mathrm{O}$ critério temporal delimita no tempo o preciso instante em que ocorreu o fato jurídico tributário. Por fim, o critério material que, entendido como o núcleo da hipótese de incidência, faz "...referência a um comportamento de pessoas, fisicas ou jurídicas, condicionado por circunstâncias de espaço e de tempo...", 52 ou seja, faz referência àquele fato capaz de fazer nascer a relação tributária tão logo ocorra no mundo dos fenômenos e que "...das duas, uma: a) ou consiste numa atividade do poder público (ou numa repercussão desta) ou, pelo contrário, b) consiste num fato ou acontecimento inteiramente indiferente a qualquer atividade estatal", ${ }^{53}$ não havendo possibilidade para um meio-termo.

48 Paulo de Barros dita que "...a descrição legislativa do fato que faz nascer a relação jurídica tributária...", chama-se hipótese tributária, enquanto que "... próprio acontecimento fáctico, enquanto evento do mundo físico, ocorrido no contexto social...", denomina-se fato jurídico tributário, acabando de uma vez por todas com a confusão criada pelo uso da expressão fato gerador (Curso..., op. cit., p. 158-60).

49 Paulo de Barros Carvalho, Curso..., op. cit., p. 154: "A hipótese alude a um fato e a conseqüência prescreve os efeitos jurídicos que o acontecimento irá propagar..."

50 Paulo de Barros Carvalho, Curso..., op. cit., p. 163. José Roberto Vieira, $A$ regra-matriz..., op. cit., p. 60 , Agui, deixamos de lado a análise da conseqüencia, por entendermos que não interessa ao presente estudo.

51 José Roberto Vieira, A regra-matriz..., op. cit., p. 63.

52 Paulo de Barros Carvalho, Curso..., op. cit., p. 166.

53 Geraldo Ataliba, Hipótese..., op. cit., p. 115.

R. Fac. Direito, Curitiba, a.28, n.28, 1994/95, p.227-248 
Assim, quando nos depararmos com um fato/acontecimento, previsto hipoteticamente como ensejador da obrigação jurídico-tributária, e no qual não haja qualquer interferência do poder público, teremos o que se conhece por tributo não-vinculado; de outra sorte, se o fato consistiu numa atuação estatal (exercício do poder de polícia, prestação de serviços públicos ou realização de obra pública que valorize imóvel particular, estamos diante dos tributos vinculados). ${ }^{54}$

Em primeira mão, temos como tributos não-vinculados os impostos e como vinculados as taxas e as contribuições de melhoria, os quais, pela análise da hipótese de incidência de cada um deles, são indiscutivelmente autônomos. Ora, são três diferentes hipóteses tributárias: os impostos diferem daquelas pois, como manda a sistemática da nossa Constituição, devem ser instituídos e cobrados em virtude de um fato qualquer (possuir propriedade, prestar serviços) que não diga com uma atuação do Poder Público (Art. 145 , I, da $\mathrm{CF} / 88$, e art. 16, CTN); já as taxas seriam cobradas em virtude de uma atividade estatal referente direta e imediatamente ao contribuinte (Art. 145, II, CF/88, e art. 77, CTN); e as contribuições de melhoria, pela valorização de imóvel de particular decorrente de obra pública, isto é, de uma atuação estatal indiretamente (mediatamente) referida ao particular (Art. 145, III, da CF, e art. 81, do CTN).

A distinção, por sua vez, entre estes dois tributos vinculados, é feita, segundo Ataliba, pelo critério da referibilidade: ${ }^{55}$ a hipótese de incidência das contribuições de melhoria contém um plus no sentido de que não basta somente a atuação estatal para que possa haver a cobrança, devendo ver-se configurada uma mais-valia no imóvel do possível contribuinte.

Por outro lado, é de se sublinhar que a discussão travada no âmbito dos defensores desta posição diz, em verdade, com a situação das con-

54 Geraldo Ataliba. Hipótese..., op. cit., p. 116: No caso dos tributos vinculados, "... a lei põe uma atuação estatal no aspecto material da h.i.", enquanto que para os tributos não-vinculados, "...a lei põe, como aspecto material da h.i., um fato qualquer não consistente em atividade estatal".

55 Geraldo Ataliba, Hipótese..., op. cit., p. 129. "A h.i. da contribuição de melhoria é a valorização imobiliária causada por obra pública" (p. 150), importante salientar que a posição deste autor sobre a estrutura lógica da norma tributária é diversa da posição do prof. Paulo de Barros, que é a adotada no presente texto. 
tribuições especiais (ou sociais ou parafiscais) e - em menor grau - dos empréstimos compulsórios, dispostos nos arts. 149 e 148, da CF/88, respectivamente. Vejamos o por quê.

Um primeiro aspecto a ser abordado é a questão da linguagem do legislador, a qual, como lembra Paulo de Barros, ...é uma linguagem natural, penetrada, em certa porção, por termos e locuções técnicas. Nem poderia ser de outra maneira. Os membros das Casas Legislativas, em países que se inclinam por um sistema democrático de governo, representam os vários segmentos da sociedade...o que confere um forte caráter de heterogeneidade, peculiar aos regimes que se queiram representativos. Portanto, ponderações ...desse jaez nos permitem compreender o porquê dos erros, impropriedades, atecnias, deficiencias e ambigüidades que os textos legais cursivamente apresentam ${ }^{56} \mathrm{e}$, particularmente, aqueles referentes às contribuições especiais.

Aqui, é de suma importância o art. $4^{\circ}$, do CTN, que, dispondo ser o fato gerador do tributo o elemento que determinará a sua (do tributo) natureza jurídica, ${ }^{57}$ descarta para tanto o nome e a destinação da exação tributária. Assim, os empréstimos compulsórios e as contribuições especiais: a) não podem figurar como espécies diversas dos impostos, das taxas e das contribuições de melhoria somente porque possuem nomes diversos destes; e b) nem podem ter como elemento autonomizador o fato de que ambos possuem uma destinação específica: o primeiro é restituível; as segundas visam atender ao sistema previdenciário, aos interesses de categorias profissionais e etc.

Todavia, se o Constituinte, ao trabalhar com os art. 148 e 149, não explicitou a sua adesão à teoria dos tributos vinculados e não-vinculados, como o fez com relação às espécies do art. 145 , da $\mathrm{CF} / 88,{ }^{58}$ porque (afora a questão nominativa) deixou transparecer, em maior grau, a finalidade e 0 motivo para a instituição das contribuições especiais e dos empréstimos

56 Paulo de Barros Carvalho, Curso..., op. cit., p. 04.

57 Por outro lado, concordamos čom a boa doutrina no sentido de que a Constituição de 1988 não deixou mais dúvidas (arts. $154, \mathrm{I}$, e $145, \S 2^{\circ}, \mathrm{CF} / 88$ ) no sentido de hoje ser a base de cálculo, também, elemento de extrema importância para a caracterização da natureza jurídica dos tributos.

58 Sobre a questäo, v.: Sacha Calmon Navarro Coêlho, Comentários...,op. cit., p. 04-15.

R. Fac. Direito, Curitiba, a. 28 , n.28, 1994/95, p. 227-248 
compulsórios, tornou a redução destes dois tributos a impostos ou taxas possível, como ensina Sacha Calmon. ${ }^{59}$

É neste particular, então, que os defensores da teoria tripartida apresentam algumas divergências.

Geraldo Ataliba entende que, segundo a sistemática constitucional, são espécies tributárias autônomas os impostos, as taxas e as contribuições. ${ }^{60}$ Para ele, com base nas lições de A. D. Giannini, ${ }^{61}$ a contribuição de melhoria, além de ser a mais típica das contribuições, ${ }^{62}$ é, ainda, a única que, como tal, se conhece em nosso ordenamento jurídico, pois, conceituando o gênero contribuição como ...o tributo vinculado cuja h.i. consiste numa atuação estatal indireta e mediatamente (mediante uma circunstância intermediária) referida ao obrigada... ${ }^{63}$ ou, ainda, como a ...prestação pecuniária exigida de pessoas que causam despesa especial ou recebem beneficio especial de uma atuação estatal..., ${ }^{64}$ as demais contribuições (arts. $149 ; 195$, I a III e $\S 8^{\circ} ; 201, \S \S 1^{\circ}$ e $7^{\circ} ; 212, \S 5^{\circ} ; 239, \S 4^{\circ}$ e 240), até agora criadas, sempre tiveram a natureza de imposto, ${ }^{65}$ apesar de possuírem regime especial (ou melhor, destinação especial), como seria o caso daquelas criadas para atender à previdência social.

Todavia, se o legislador quisesse, contando é claro com uma boa assessoria, poderia "...estruturar contribuição pura", ${ }^{66}$ que deve dife-

59 Sacha Calmon N, Coêlho, Comentários..., op. cit., p. 09-10.

60 Geraldo Ataliba, Hipótese de incidência..., op. cit., p. 111: "A Constituição de 1988 refere-se a impostos, taxas e contribuições..."

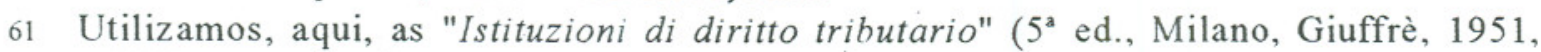
p.527), quando Giannini apontava ser os tributti di miglioria "...una prestazione dovuta... da coloro che trovandosi in una determinata situazione, risentono un particulare vantaggio economico, per effetto della esplicazione di un'attività amministrativa..." e o contributo integrativo della utenza stradale, como "...una prestazione dovuta... da coloro che, in conseguenza delle cose da essi possedute, o dell'esercizio di un'industria, di un commercio o di altra attività, provocano una spesa o una maggiore spesa dell'ente pubblico", ambas figuras constituindo o que denominou tributti speciale, que são diversos das taxas e dos impostos (op. cit., p. 41).

62 Geraldo Ataliba, Hipótese de incidencia..., op. cit., p.150 e 161.

63 Geraldo Ataliba, Hipótese de incidência..., op. cit., p. 134.

64 Geraldo Ataliba, Hipótese de incidencia..., op. cit., p. 178.

65 Geraldo Ataliba, Hipótese de incidencia..., op. cit., p. 182.

66 Geraldo Ataliba, Hipótese de incidência..., op. cit., p. 160. 
rençar-se da contribuição de melhoria em razão da atuação estatal ser provocante ou provocada por uma situação (elemento intermediário, ou seja, aquele quid utilizado para a diferenciação entre as taxas e as contribuições): a) as contribuições de melhoria são cobradas porque uma atuação estatal (construção de uma obra pública) provocou uma conseqüência (valorização do imóvel) referida ao obrigado, enquanto que $b$ ) as demais contribuições são cobradas porque, por exemplo, o obrigado ...desenvolve uma atividade que causa uma situação..., a qual, por sua vez, provoca uma atuação pública. ${ }^{67}$

Por fim, em sendo a base de cálculo um importante elemento para caracterizar a natureza jurídica do tributo, Ataliba conclui que Se "verdadeira" a contribuição, a base estará ou na causa provocante (ou ensejante) da ação estatal, ou na sua conseqüência ou efeito, fatos estes legalmente qualificados para desencadearem o efeito de, se acontecidos e quando acontecidos, darem nascimento a obrigações tributárias. ${ }^{68}$

Quanto aos empréstimos compulsórios, Ataliba, conforme o seu Sistema Constitucional Tributário Brasileiro, ${ }^{69}$ adotou, desde então, 0 posicionamento já citado de Becker e Baleeiro, entendendo serem aqueles impostos restituíveis.

Apesar de seguido por Rubens Gomes de Souza, ${ }^{70}$ J. A. Lima Gonçalves, ${ }^{71}$ Hamilton Dias de Souza ${ }^{72}$ e outros mais, este posicionamento de Ataliba quanto às contribuições e aos empréstimos compulsórios não se fez dominante dentre aqueles que defendem a teoria tripartida.

67 Geraldo Ataliba, Hipótese de incidência..., op. cit., p. 163.

68 Geraldo Ataliba, Hipótese de incidência..., op. cit., p. 173.

69 Geraldo Ataliba, Sistema constitucional..., op. cit., p. 289.

70 Sobretudo, v.: Rubens Gomes de Souza, Geraldo Ataliba; Paulo de Barros Carvalho,

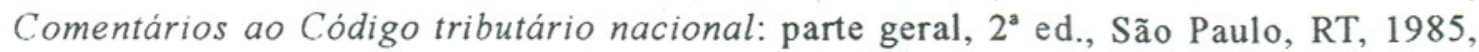
141 p.; Rubens Gomes de Souza. "Natureza tributária de contribuição para o FGTS", in: Revista de direito público, São Paulo, RT, jul./set.-1971, n. 17, p. 308-11; e Rubens Gomes de Souza. "A Previdência Social e os municípios", in: Revista de Direito Público, São Paulo, RT, abr./jun.-1973, n.24, p. 232-3.

71 J. A. Lima Gonçalves, Isonomia na norma tributária, São Paulo, Malheiros, 1993, p.57-9.

72 Hamilton Dias de Souza, Tributos federais..., op. cit., p. 311, Sobre empréstimos compulsórios, verificar nota de roda pé n. 02, do presente texto.

R. Fac. Direito, Curitiba, a.28, n.28, 1994/95, p.227-248 
Temos, por outro lado, o posicionamento encabeçado por Paulo de Barros Carvalho, entendendo que $a$ ) as espécies tributárias autônomas são $o s$ impostos, as taxas e as contribuições de melhoria; b) os empréstimos compulsórios poderão revestir qualquer das formas destas três espécies tributárias, ${ }^{73}$ e c) as demais contribuições, por ele designadas de contribuições sociais, podem tanto assumir feição de taxa como de imposto, mas nunca de contribuição de melhoria, ${ }^{74}$ no que é seguido, em certa medida, por vários autores como Sacha Calmon Navarro Coêlho, ${ }^{75}$ José Roberto Vieira, ${ }^{76}$ Américo Masset Lacombe, ${ }^{77}$ Roque Antonio Carrazza ${ }^{78}$ (este, ao entender, por igual, que são espécies tributárias os impostos, as taxas e as contribuições de melhoria, diverge quanto aos empréstimos compulsórios que, para ele, de regra, "...assumem a natureza jurídica de impostos" ${ }^{179}$ e quanto às contribuições sociais, ...referidas no art. 149 e seu parágrafo único, da Constituição..., que ...são tributos (impostos, taxas ou contribuição de melhoria)... ${ }^{80}$

Marco Aurélio Greco, ${ }^{81}$ Edvaldo Brito, ${ }^{82}$ José Afonso da Silva, ${ }^{83}$ Régis Fernandes de Oliveira, ${ }^{84}$ Estevão Horvath, ${ }^{85}$ Flávio Bauer Novelli, ${ }^{86}$

73 Paulo de Barros Carvalho, Curso..., op. cit., p. 27.

74 Paulo de Barros Carvalho, Curso..., op. cit., p. 35-6.

75 Sacha Calmon Navarro Coêlho, Comentários... op. cit., p. 09-10.

76 José Roberto Vieira, O sistema e a administração tributários brasileiros. Trabalho apresentado no XIII Curso de Instituciones e Técnicas Tributarias, na Escuela de la Hacienda Pública del Instituto de Estudios Fiscales, Madrid, Espanha, 1993, inédito, p.09-10.

77 Américo M. Lacombe, Contribuições profissionais, São Paulo, RT, 1987, p. 38-40.

78 Roque A. Carrazza, Curso de direito constitucional tributário, $4^{a}$ ed., São Paulo, Malheiros, 1993, $471 \mathrm{p}$.

79 Roque Antonio Carrazza, Curso.... op. cit., p. 297.

80 Roque Antonio Carrazza, Curso..., op. cit., p. 305.

81 Marco A. Greco. "Perfil do sistema constitucional tributário brasileiro". Apêndice. in: Os sistemas fiscais, Pierre Beltrame, Coimbra, Almedina, 1976, p. 183-4.

82 Edvaldo Brito, As taxas... op. cit., p. 26. No caso deste autor, ressalva-se o fato de que os empréstimos compulsórios, assim como as demais contribuições, não são tributos. mas, sim, prestações compulsórias não tributárias.

83 José Afonso da Silva, Curso de direito constitucional positivo, $6^{\mathrm{a}}$ ed., São Paulo, RT, 1990 , p. $590-1$.

84 Régis Fernandes de Oliveira, Receitas públicas originárias, São Paulo, Malheiros, 1994, p. 81-3.

85 Estevão Horvath, Empréstimos..., op. cit., p. 267.

86 Flávio B. Novelli, Taxa-apontamentos sobre o seu conceito juridico, in: Revista de Direito Tributário, São Paulo, Malheiros, n. 59, p. 100. 
Nilton Latorraca, ${ }^{87}$ Yoshiaki Ichihara ${ }^{88}$ Heron Arzua, ${ }^{89}$ Sidney Saraiva Apocalypse, ${ }^{90}$ José Ribamar Ferreira, ${ }^{91}$ no Brasil, e Achille Donato Giannini, ${ }^{92}$ Gian Antonio Micheli, ${ }^{93}$ José Luis Perez de Ayala, ${ }^{94}$ Carlos A. Mersán, ${ }^{95}$ no exterior, adotam, também, mas com algumas particularidades, a teoria tripartida.

\section{Conclusões}

Dentre as várias formas de se encarar o fenômeno jurídico, optamos por aquela que identifica o direito com o ordenamento jurídico. ${ }^{96}$

A vasta gama de normas jurídicas existentes em nosso ordenamento, leva-nos, no caso do direito tributário, a encarar ... aquela que imputa a uma certa situação fática, descrita idealmente, uma conseqüencia peculiar,

87 Nilton Latorraca, Direito tributário: imposto de renda das empresas, $12^{\mathrm{a}}$ ed., São Paulo, Atlas, 1990, p. 30-2.

88 Yoshiaki Ichiara, Direito tributário: uma introdução, 2a ed.. São Paulo, Atlas, 1987, p. 50-3.

89 Heron Arzua. "Contribuições na Constituição de 1988," In Revista de Direito Tributário, São Paulo. RT, a. 13, jul./set.-1989, n 49, p. 132-4.

90 Sidney S. Apocalypse, "Sistema constitucional tributário brasileiro", in Revista de Direito Tributário, São Paulo, RT, a. 13, jul./set.-1989, n. 49, p. 155.

91 José R. Ferreira. Curso de direito financeiro, São Paulo, Saraiva, 1979, p. 57-8.

92 Achille D. Giannini, Instituzioni... op. cit., 527 p.

93 Gian A. Micheli, Curso de direito tributário, trad. Marco A. Greco e Pedro L. Marrey Jr., São Paulo, RT, 1978, p. 75-86.

94 José L. Perez de Ayala, Derecho tributario I, Madrid, Editorial de Derecho Financeiro, 1968 , p. $48-58$.

95 Carlos A. Mersan. Direito tributário, $2^{\mathrm{a}}$ ed., Trad. Dejalma de Campos, São Paulo, RT, 1988 , p. 25-8.

96 Marçal Justen Filho, O imposto sobre serviços na Constituição, São Paulo, RT, 1985, p. 12, muito embora concordemos com Marcelo Neves (Teoria da inconstitucionalidade das leis, São Paulo, Saraiva, 1988, p. 08 e 16, respectivamente) quanto ao fato de que: "O Direito...caracteriza-se como um sistema pluridimensional, assimétrico e dialético. Os reducionismos jusnaturalistas, positivistas ou realistas são, portanto, teoricamente insuficientes não só a uma abordagem de síntese ontológica global do fenômeno jurídico, mas também no que se refere às abordagens parciais" e "O ordenamento jurídico é uma das dimensões essenciais do complexo fenômeno jurídico. Constitui-lhe o aspecto formal-normativo".

R. Fac. Direito, Curitiba, a.28, n.28, 1994/95, p. 227-248 
consistente no nascimento de uma relação juridica pela qual alguém está obrigado a levar dinheiro aos cofres do Estado, ${ }^{97}$ ou seja, a norma primária (segundo a supracitada distinção de Kelsen).

Desde Becker, sabemos que o aspecto material da norma primária é o critério jurídico fundamental para se estabelecer o gênero e a espécie tributária. ${ }^{98}$ Este aspecto material (tendo em mente o seccionamento da hipótese tributária) faz referência a um comportamento de pessoas, que, ocorrido no mundo dos fenômenos, dará nascimento à relação jurídicatributária. Este fato, ou será vinculado a uma atuação estatal ou não. Neste segundo caso, colocamos os impostos e, no primeiro, as taxas e a contribuição de melhoria.

Quanto aos empréstimos compulsórios, dificilmente poderão eles ter natureza jurídica outra que não seja a de imposto (restituível, o que não vem ao caso).

As demais contribuições (aqui denominadas contribuições especiais), sem, em momento algum, adotarem caráter híbrido, a nosso ver, são redutíveis apenas aos impostos (ou, ainda, às taxas), porque, (a) ao contrário dos demais sistemas alienígenas, o nosso, no tratamento constitucional da matéria tributária, foi rígido e exaustivo, impossibilitando, de certo modo, o uso do método comparativo; e (b) se se adotou, claramente, a teoria dos tributos vinculados e não-vinculados para com o art. 145, fazendo-se diferenciar, primeiramente, os impostos das taxas e da contribuição de melhoria pelo ângulo da atuação estatal e, em seguida, as taxas da contribuição de melhoria pelo critério, já exposto, da referibilidade, não há como dizer que, no tocante às contribuições especiais, a Carta Magna estivesse por englobá-las, juntamente, com a contribuição de melhoria, em uma espécie sub-divisível. Não. Quando se fala em contribuição de melhoria ou contribuições especiais, devemos volver os olhos para o art. $4^{\circ}$, do

97 Marçal Justen Filho, $O$ imposto..., op. cit., p. 41.

98 Ocorre que, para este autor, o aspecto material era if́tegrado pela base de cálculo, o que, não é mais aceito. Atualmente, como dissemos, a boa doutrina continua a entender que a base de cálculo é (outro) dado fundamental para a caracterização da natureza jurídica dos tributos, mas ela se encontra no mandamento e não na hipótese de incidência como queria o falecido jurista gaúcho. 
CTN, para lembrando que o nome não pode caracterizar a natureza de um tributo.

Quanto a isto, somente podemos dizer que a Constituição estampa, erroneamente, de um lado, uma espécie chamada contribuição (de.melhoria) e, de outro, tributos chamados contribuições (especiais), que melhor seriam chamados de impostos (ou taxas) especiais, pois em nada se confundem com aquela outra figura tributária. E se, pelo significante contribuição, somente podemos entender as contribuições de melhoria e aquelas outras designadas por Giannini, então, em nosso ordenamento, conforme disse Ataliba, não existem verdadeiras contribuições.

Por ora, estamos convencidos de que a posição sustentada por Paulo de Barros, dentre outros, quanto às contribuições sociais (especiais), continua a ser aquela que melhor se coaduna com a nossa sistemática constitucional-tributária. Temos, então, que as espécies tributárias autônomas em nosso ordenamento jurídico-tributário são os impostos, as taxas e as contribuições de melhoria, sendo a) que os empréstimos compulsórios configuram-se como impostos (possível teoricamente como taxas) e as contribuições especiais, como impostos ou taxas.

\section{Referências Bibliográficas}

APOCALYPSE, Sidney Saraiva. "Sistema constitucional tributário brasileiro." in Revista de Direito Tributário. São Paulo: RT. a. 13. jul./set.-1989, n. 49, p. 154-7.

ARZUA, Herón. "Contribuições na Constituição de 1988." in Revista de Direito Tributário. São Paulo: RT. a. 13. jul./set.-1989, no 49. p. 130-4.

ATALIBA, Geraldo. Natureza jurídica da contribuição de melhoria. São Paulo: RT, 1964, 263p.

Sistema constitucional tributário brasileiro. São Paulo: RT, 1968, 295p.

. Apontamentos de ciência das finanças, direito financeiro e tributário. São Paulo: RT, abril-1969, 324p.

. "Considerações em torno da teoria jurídica da taxa." in Revista de Direito Público.

São Paulo: RT. a. 2. jul./set.-1939, n. 09. 1969, p. 43-54.

. Hipótese de incidência tributária. 5 ed. São Paulo: Malheiros, 1992, 182p.

AYALA, José Luis Perez de. Derecho tributario I. Madrid: Editorial de Derecho Financiero, 1968, 370p.

BALEEIRO, Aliomar. Direito tributário brasileiro. $9^{\mathrm{a}}$ ed. Rio de Janeiro: Forense, 1977, $632 \mathrm{p}$. 
Limitações ao poder de tributar. $5^{\mathrm{a}}$ ed. Rio de Janeiro: Forense, 1977, 419p.

BASTOS, Celso Ribeiro. Curso de direito financeiro e de direito tributário. São Paulo: Saraiva, 1991, 273p.

BATALHA, Célio de Freitas. "Lei complementar em matéria tributária." in Revista de Direito Tributário. São Paulo: RT. a. 13. jul./set.-1989. n 49. p. 121-9.

BECKER, Alfredo Augusto. Teoria geral do direito tributario. $2^{\text {a }}$ ed. São Paulo: Saraiva. 1972, 621p.

BORGES, Arnaldo. Introdução ao direito tributario. São Paulo: RT, 1992, 64p.

BRITO, Edvaldo Pereira de. "As taxas." In: $43^{\text {rd }}$ Congress of the International Fiscal Association. Seminário "E": El sistema tributario brasileño. São Paulo: Acadêmica. 1989. p. 16-53.

BUJANDA, Fernando Sainz de. "Estructura juridica del sistema tributário. in Revista de Derecho Financiero y de Hacienda Pública. Madrid. 1961, vol. IX. fasc. 41.

CARRAZZA, Roque Antônio. Curso de direito constitucional tributário. $4^{\mathrm{a}}$ ed. São Paulo: Malheiros, 1993, 471p.

CARVAlHO, Paulo de Barros. Teoria da norma tributária. $2^{\text {a }}$ ed. São Paulo: RT, 1981. 123p. Curso de direito tributário. $5^{\text {a }}$ ed. São Paulo: Saraiva, 1991, 374p.

CASSONE, Vittorio. Sistema tributário constitucional na Constituição de 1988. $3^{\circledR}$ ed. São Paulo: Atlas.

COELHO, Sacha Calmon Navarro. Comentários à Constituição de 1988: sistema tributário. $5^{\mathrm{a}}$ ed. Rio de Janeiro: Forense, 1993, 423p.

DENARI, Zelmo. Curso de direito tributário. $2^{\mathrm{a}}$ ed. Rio de Janeiro: Forense. 1991. 349p.

FANUCHI, Fabio. Curso de direito tributário. v. I. 4 ed. São Paulo Resenha Tributária. 1986. $594 \mathrm{p}$.

FERREIRA, José Ribamar. Curso de direito financeiro. São Paulo: Saraiva. 1979, 150p.

FERREIRA FILHO, Manoel Gonçalves. Comentários a Constituição brasileira de 1988. v. 3. São Paulo: Saraiva, 1994.

COLLARILE, Lúcia Valle Figueiredo. "Sentença proferida sobre empréstimos compulsórios." apud HORVATH, Estevão. "Empréstimo compulsório sobre veiculos."in Revista de Direito Tributário. São Paulo: RT. a. 12. jan./mar.-1988, n. 43. p. 252-65.

GASTALDI, José Petrelli. Iniciação ao curso de direıto tributário. São Paulo: Saraiva, 1965, $122 \mathrm{p}$.

GONÇALVES, José Artur Lima. Isonomia na norma tributária. São Paulo: Malheiros. 1993. p.78

GRECO, Marco Aurélio. "Perfil do sistema constitucional tributário brasileiro". Apêndice. in: Os sistemas fiscais, BELTRAME, Pierre. Coimbrá. Almedina. 1976, p. 181-213.

ICHIHARA, Yoshiaki. Direito tributário: uma introdução. $2^{a}$ ed. São Paulo: Atlas, 1987. $164 \mathrm{p}$.

JARDIM, Eduardo Marcial Ferreira. Manual de diretto financeiro e tributárı. São Paulo: Saraiva, 1993, 272p.

Instituições de direito tributário, São Paulo: Aquarela, 1988, 199p.

R. Fac. Direito, Curitiba, a.28, n.28, 1994/95. p.227-248 
JUSTEN FILHO, Marçal. O imposto sobre serviços na Constituição. São Paulo: RT, 1985, $187 \mathrm{p}$.

KELSEN, Hans. Teoria geral das normas. trad. José F. Duarte. Porto Alegre: Safe, 1986, $509 \mathrm{p}$.

LACOMBE, Américo Masset. Contribuições profissionais. São Paulo: RT, 1987, 88p.

LATORRACA, Nilton. Direito tributário: imposto de renda das empresas. $12^{\mathrm{a}}$ ed. São Paulo: Atlas, 1990, 392p.

MACHADO, Hugo de Brito. Curso de direito tributário. $7^{\text {a }}$ ed. São Paulo: Malheiros, 1993, $365 p$.

MARTINS, Ives Gandra da Silva. As contribuições especiais numa divisão qüinqüipartida dos tributos. São Paulo: Editora Resenha Tributária, 1976.

. Comentários à Constituição do Brasil. v. 6, t. I. São Paulo: Saraiva, 1990, 582p.

. "Quota de contribuição sobre açúcar e álcool - adicional - inconstitucionalidade." in

Revista de Direito Tributário. São Paulo: RT. a. 12. jan./mar.-1988, n. 43. p. 167-80.

Curso de direito tributário (org.). v. 2, $2^{\text {a }}$ ed. Belém: CEJUP, 1993, p. 95-104.

MAYA, Rômulo. "Das contribuições especiais na Constituição de 1988." in Revista de Direito Tributário. São Paulo: RT. a. 13. out/dez-1989, n. 50. p. 68-71.

MELO, José Eduardo Soares. Contribuições sociais no sistema tributário. São Paulo: Malheiros, 1993, 207p.

MERSÁN, Carlos. Direito tributário. $2^{\text {a }}$ ed. Trad. Dejalma de Campos. São Paulo: RT, 1988, $376 \mathrm{p}$.

MICHELI, Gian Antonio. Curso de direito tributário. Trad. Marco A. Greco e Pedro L. Marrey Jr. São Paulo: RT, 1978, 269p.

MIRANDA, Pontes de. Comentários à Constituição de 1967. v. II. São Paulo: RT, 1967, $580 \mathrm{p}$.

NEVES, Marcelo. Teoria da inconstitucionalidade das leis. São Paulo: Saraiva, 1988, 178p.

NOVELLI, Flávio Bauer. "Taxa-apontamentos sobre o seu conceito jurídico." in Revista de Direito Tributário. São Paulo: Malheiro. n. 59. s/d. p. 95-123.

OLIVEIRA, Regis Fernandes de. Receitas públicas originárias. São Paulo: Malheiros, 1994, $180 \mathrm{p}$.

PEROGORDO, Juan José Bayona de; ROCH, María Teresa Soler. Derecho Financiero. Alicante: Compas, 1987, 740p.

ROSA JUNIOR, Luiz Emygdio F. da. Manual de direito financeiro e de direito tributário. $5^{\text {a }}$ ed. Rio de Janeiro: Freitas Bastos, 1985, 518p.

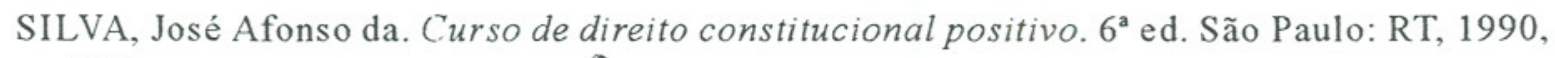
$756 \mathrm{p}$.

SOUZA, Hamilton Dias de. "Tributos federais". in: A Constituição Brasileira 1988: interpretações. Rio de Janeiro: Forense Universitária. 1988, p. 311-21.

SOUZA, Rubens Gomes de; ATAliBA, Geraldo; CARVALHO, Paulo de Barros. Comentários ao código tributário nacional: parte geral. $2^{a}$ ed. São Paulo: RT, 1985, $141 \mathrm{p}$.

R. Fac. Direito, Curitiba, a.28, n.28, 1994/95, p.227-248 
SOUZA, Rubens Gomes de. "Natureza tributária da contribuição para o FGTS." in Revista de Direito Público. São Paulo: RT. a. IV. jul./set.-1971, n. 17. p. 305-21.

SOUZA, Rubens Gomes de. "A Previdência Social e os municípios." in Revista de Direito Público. São Paulo: RT. a. VI. abr./jun.-1973, n. 24, p. 215-69.

SPISSO, Rodolfo R. Derecho constitucional tributario. Buenos Aires: Depalma, 1993, 490p.

VIEIRA, José Roberto. O sistema e a administração tributários brasileiros. Trabalho apresentado no XIII Curso de Instituciones e Técnicas Tributarias, na Escuela de la Hacienda Pública del Instituto de Estudios Fiscales. Madrid: Espanha, 1993, inédito.

. A regra-matriz de incidência do IPI: texto e contexto. Curitiba: Juruá, 1993, 179p.

VILLEGAS, Héctor. Curso de direito tributário. Trad. por Roque Antonio Carrazza. São Paulo: RT, 1980, 162p. 